\title{
Yaşılıarda görülen kalça kırıklarında hangi kırığa osteosentez ve nasıl?
}

\section{Osteosynthesis for which fracture in hip fractures in the elderly patients and how?}

\author{
Cem Dinçay Büyükkurt ${ }^{1}$, Ali Yüce ${ }^{2}$ \\ 'SBÜ Prof. Dr. Cemil Taşçıoğlu Şehir Hastanesi, Ortopedi ve Travmatoloji Kliniği, İstanbul \\ ${ }^{2}$ Başakşehir Çam ve Sakura Şehir Hastanesi, Ortopedi ve Travmatoloji Kliniği, İstanbul
}

\begin{abstract}
Dünyada yaşanan hızlı nüfus artışı ve beklenen yaşam süresinin uzaması nedeniyle kalça kırığı görülme sıklığı artmaktadır. Bu kırıklar, özellikle yaşlı hastalarda görülen mortalite ile yakın ilişkilidir. Kalça kırığı tedavisinde temel amaç hastaya ağrısız ve işlevsel bir ekstremite sağlamaktır. Kalça kırıkları, kapsül dışı ve kapsül içi kırıklar olarak iki grupta incelenebilir. Kapsül içi kırıklar, femur başı ile trokanter arasındaki bölgede yer alan proksimal femur kırıklarıdır. Yaşlı ayrışmamış ya da daha az ayrışmış femur boyun kırıklarında, ilk tercih osteosentez olabilir. Ayrışmış kırıklarda 70 yaş altı hastalarda ilk tercih osteosentez olabilirken; 70 yaş üstü olgularda eklemde artroz varlığı, gecikmiş kırıklar, femur başında avasküler nekroz varlığı, hastanın genel durumu ve ek hastalıkları gibi faktörler dikkate alınarak osteosentez ya da artroplasti arasındaki tedavi kararı değerlendirilmelidir. Kapsül dışı femur proksimal kırıklarında amaç, hastanın erken hareketini sağlayan kararlı tespiti elde etmektir. Stabil intertrokanterik kırığı bulunan yaşlı hastalarda öncelikle önerilen tedavi osteosentezdir. İpsilateral kalça osteoartriti, femur başının ipsilateral avasküler nekrozu, enflamatuvar artrit, kötü kemik kalitesine sahip instabil kırık paterni, ihmal edilmiş kırıklar ve başarısız internal tespit yapılmış olan seçilmiş bir hasta alt grubunda ilk seçenek olarak hemiartroplasti önerilmektedir. Bu sayılanlar haricindeki tüm olgularda osteosentez birinci tedavi yöntemi olarak tercih edilmelidir. Ameliyat öncesi planlamada ameliyathane şartları, traksiyon masası, eğitimli personel varlığı, mevcut implantlar ile uygulama setlerinin özellikleri ve cerrahın tecrübesi temel öneme sahiptir. Sonuç olarak yaşlı kalça kırıklarında uzayan yaşam süreleri ve artan konfor beklentileri göz önüne alındığında öncelikli tedavi tercihi hastanın kendi kalçasını kullanmasına izin veren yöntemler olarak ortaya çıkmaktadır.
\end{abstract}

Anahtar sözcükler: kalça kırı̆̆ı; proksimal femur kırı̆̆ı; osteosentez; artroplasti
The frequency of hip fractures is increasing due to the rapid population growth in the world and the prolonged life expectancy. Hip fracture is closely related to mortality, especially in elderly patients. The main purpose of hip fracture treatment is to provide the patient with a painless and functional extremity. Hip fractures can be examined in two groups as extracapsular and intracapsular fractures. Intracapsular fractures are proximal femoral fractures located in the area between the femoral head and trochanter. Osteosynthesis may be the first choice in elderly nondisplaced or minimally displaced femoral neck fracture. First-choice osteosynthesis may be preferred treatment method in patients under 70 years of age in displaced fractures. In patients over 70 years of age, the treatment decision between osteosynthesis or arthroplasty should be evaluated considering factors such as the presence of hip arthrosis, delayed fractures, presence of avascular necrosis in the femoral head, the general condition of the patient, difficulties in receiving anesthesia and the need for early mobilization. The aim in extracapsular femur proximal fractures is to achieve stable fixation that enables early mobilization of the patient. In elderly patients with stable intertrochanteric fractures, primarily recommended treatment is osteosynthesis. Hemiarthroplasty is recommended as the first choice in a selected subgroup of patients with ipsilateral hip arthrosis, ipsilateral avascular necrosis of the femoral head, inflammatory arthritis, unstable fracture pattern with poor bone quality, neglected fractures, and unsuccessful internal fixation. Osteosynthesis should be preferred as the first treatment method in all cases except those listed. In preoperative planning, operating room conditions, traction table, the presence of trained stuff, the features of the existing implants and application sets and the surgeon's experience are of fundamental importance. As a result, considering the prolonged lifetime and increasing comfort expectations in elderly hip fractures, the primary treatment choice emerges as methods that allow the patient to use his own hip.

Key words: hip fracture; proximal femoral fracture; osteosynthesis; arthroplasty

- İletişim adresi: Uzm. Dr. Cem Dinçay Büyükkurt, SBÜ Prof. Dr. Cemil Taşçıoğlu Şehir Hastanesi, Ortopedi ve Travmatoloji Kliniği, Darülaceze Caddesi No: 27 Okmeydanı, Şişli, İstanbul Tel: 0532 - 5786440 e-posta: cemdincay@yahoo.com 


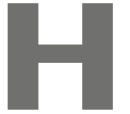

er yıl dünya çapında 1,6 milyondan fazla kalça kırığı meydana gelmektedir. Bu sayı, nüfus artmaya devam ettikçe her on yılda bir \%25 oranında artmaktadır. ${ }^{[1,2]}$ Yaşlı hastalar arasında kalça kırığı, yılda \%14 ile \%36 arasında değişen ölüm oranlarında görülmektedir. ${ }^{[3]}$

Kalça kırığı tedavisinde amaç ağrıyı azaltmak ve hastaların travma öncesi işlev düzeylerine dönmesini sağlamaktır. ${ }^{[4]} \mathrm{Bu}$ olgularda uzun süreli yatağa bağımlı kalma ile ilişkili olarak artmış morbidite ve mortalite göz önüne alındığında, cerrahi tedavi gerekliliği tartışmasızdır. ${ }^{[5]}$ Yaşlı hastalarda düşük kemik kalitesine bağlı olarak tedavide osteosentez seçeneği yüksek komplikasyon oranlarıyla ilişkilendirilebilir. ${ }^{[6]}$ Kalça kırıkları, kapsül dışı ve kapsül içi kırıklar olarak iki grupta değerlendirilebilir (Şekil 1). ${ }^{[7]}$

\section{FEMUR BOYUN KIRIKLARI}

Femur boyun kırıklarının çoğunluğu yaşlı hastalarda düşük enerjili travmalardan kaynaklanır. ${ }^{[8]}$ Yaşlı hastalardaki ayrışmamış femur boyun kırıkları neredeyse sadece vida osteosentezi ile tedavi edilirken, ayrışmış kırıkların tedavisi konusunda bir fikir birliği yoktur. ${ }^{[9,10]}$ Bu kırıkların osteosentezinde önerilen tedavi metodu daha az cilt insizyonu, daha az kan kaybı ve daha kısa operasyon süresi ile daha az invaziv yöntem olan kanüllü vida ile tespittir. ${ }^{[11]}$ Femur boynu kırıklarının daha az invaziv vida tespiti genellikle üç nokta prensibine göre $6,0-7,3 \mathrm{~mm}$ çapında kanüllü vida kullanılarak yapılır. Stabilizasyon, iki veya üç vidayla sağlanabilir (Şekil 2).

Literatürde kullanılacak vidaların sayısı ve en uygun konfigürasyonu konusunda fikir birliği yoktur. ${ }^{[11]}$ Biyomekanik testler, iki vidalı tespitte vida konumlan-

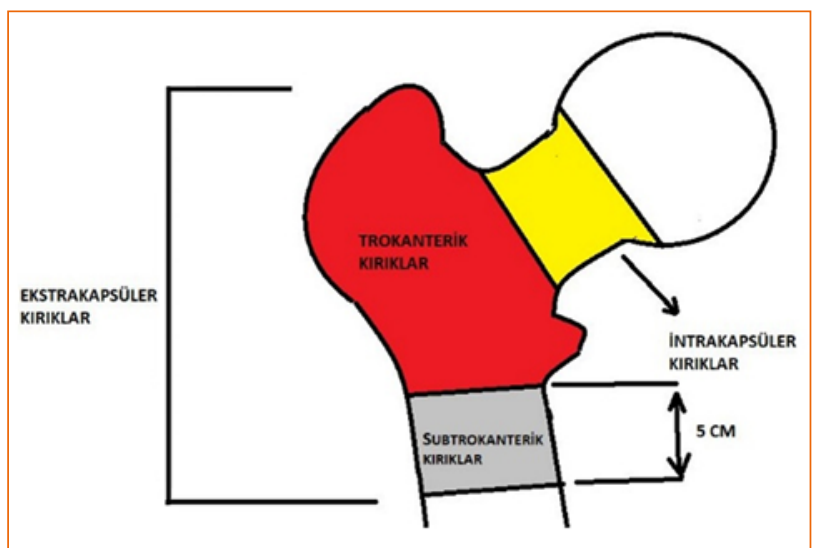

Şekil 1. Proksimal femur bölgesinde görülen kırıkların anatomik yerleşimleri. dırması dikey yerine yatay olduğunda ve femur boynunun merkezi yerine posterior ve femoral kalkara daha yakın olduğunda daha iyi sonuçlar elde edildiğini göstermiştir. Üç vida kullanırken, üçgenin tabanı kranial veya kaudal olabilir. Üçten fazla vida kullanımında herhangi bir avantaj gösterilmemiştir. ${ }^{[11]}$

Simunovic ve ark. ayrışmamış kırıklarda kansellöz vida ile kapalı osteosentezin; stabil bir yapı, daha az invaziv bir yaklaşım ve kısa ameliyat süresi sağladı̆̆ını bildirmişlerdir. Tipik olarak, üç kanüllü kansellöz vidanın ayrışmayı önlemek için boynun postero-inferior kalkar boyunca alt vida ile birlikte ters bir üçgen şeklinde yerleştirilmesini önermişlerdir. Ameliyatta dikkat edilmesi gereken hususları da vida dişlerinin kırık bölgesini geçmesini sağlamak, bir stres bölgesinden kaçınmak için küçük trokanter seviyesinde veya üzerinde bir giriş noktası kullanmak ve yaşlı ve osteoporotik kemik yapısı olan olgularda pul kullanmak olarak belirlemişlerdir. Yaşlı bireylerdeki ayrışmış kırık tiplerinde ise birincil tedavi seçeneği olarak erken harekete ve işleve dönüşe izin verdiği için kalça artroplastisini önermişlerdir. ${ }^{[3]}$

Parker ve ark., yaşlı ayrışmış femur boyun kırıklarında hemiartroplasti ile osteosentezi karşılaştırdıkları çaIışmasında, internal tespitin daha kısa anestezi süresi, daha düşük kan kaybı ve transfüzyon gereksinimine neden olduğunu göstermiştir. Bir yıllık takipte gruplar arasında mortalite oranlarında istatistiksel olarak anlamlı fark gözlememiştir. Yaralanmadan bir, iki ve üç
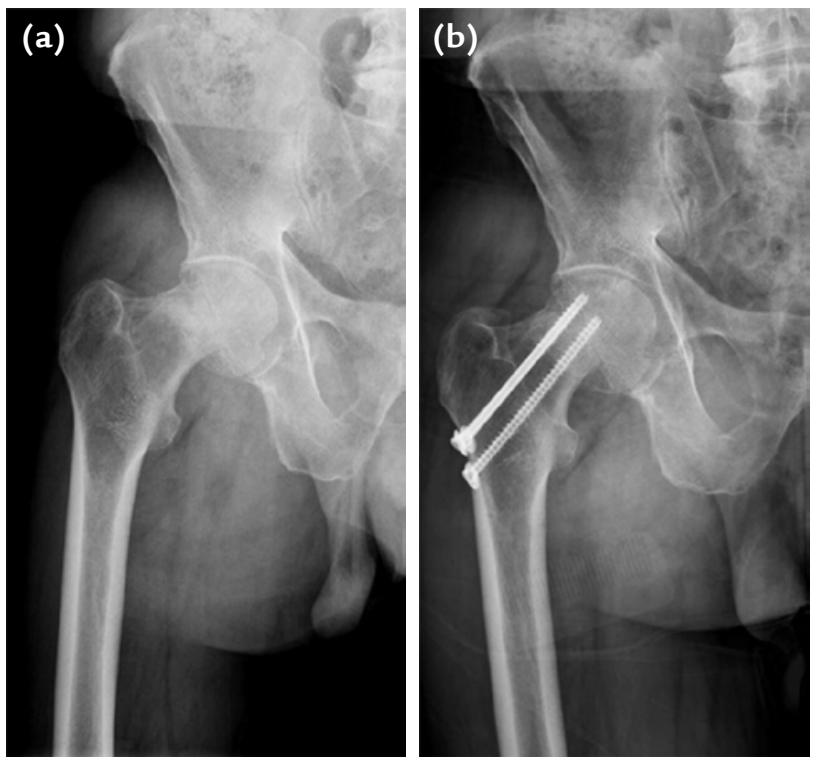

Şekil 2. a, b. Yetmiş iki yaşında erkek hasta; Garden Tip I sağ femur boyun kırığı (a), kanüllü vida ile osteosentez (b). 

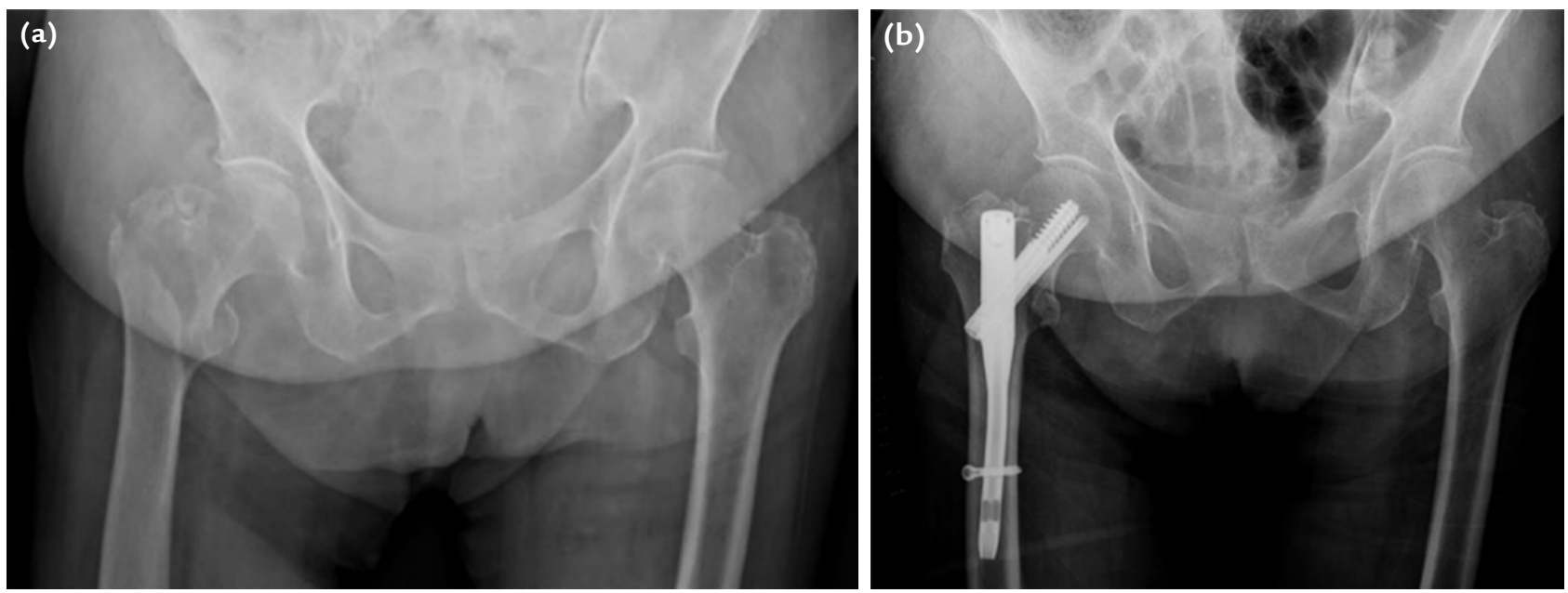

Şekil 3. a, b. Yetmiş dört yaşında kadın hasta; AO/OTA Tip A2.2 proksimal femur kırı̆̆ı (a), Proksimal femoral çivi ile osteosentez (b).

yıl sonra değerlendirdiği hayatta kalan hastalarda, ağrı ve aktivite sonuçlarını ise benzer bulmuştur. Bu çalışmada ekstremite kısalığı internal tespitten sonra daha yaygın olarak görülmüştür. Ayrışmış kapsül içi kırık için internal tespitin yaşam beklentisi iyi olan genç hastalar (yaklaşık 70 yaş altı) için uygun olduğu savunulmuş, ayrışmış kapsül içi kırı̆̆ı olan 70 yaşın üzerinde kalan hastalar için ise hemiartroplastinin ikincil cerrahi gerekliliği yönünden daha düşük risk barındırdığı sonucuna varılmıştır. ${ }^{[12]}$

Chen ve ark., 80 yaşın üzerindeki hastalarda ayrışmamış femur boyun kırıklarının tedavisi için kanüllü vida ile tespitin basit, güvenli, ekonomik ve makul derecede etkili bir yöntem olduğunu savunmuşlardır. Uygun hasta seçimi (Singh indeksi 3), cerrahi tecrübe, uygun sağlık merkezleri ve uygun ameliyat sonrası bakım (kontrollü kısmi yük verme ve düzenli röntgenografik takip) ile iyi bir prognoz elde edilebileceği görüşünü savunmuşlardır. ${ }^{[10]}$

Osteosentezle karşılaştırıldığında artroplastinin sadece cerrahi revizyonu azaltmakla kalmayan, aynı zamanda komplikasyon sıklığını da azaltan bir tedavi olduğunu öne süren yayınlar da mevcuttur. ${ }^{[9,13]}$

Yaşlı ayrışmamış femur boyun kırıklarında ilk tercih osteosentez olabilir. Ayrışmış kırıklarda 70 yaş altı hastalarda ilk tercih osteosentez olabilirken; 70 yaş üstü olgularda kalçada eklem artrozu varlığı, gecikmiş kırıklar, femur başında avasküler nekroz varlığı, hastanın genel durumu, anestezi alımına bağlı sorunlar ve erken hareket ihtiyacı gibi faktörler dikkate alınarak osteosentez ya da artroplasti arasındaki tedavi kararı değerlendirilmelidir.

\section{PERTROKANTERIK KIRIKLAR}

Pertrokanterik femoral kırıkların görülme sıklı̆̆ı son yıllarda önemli ölçüde artmıştır ve bu eğilim, nüfusun artan yaşı nedeniyle muhtemelen yakın gelecekte de artış göstermeye devam edecektir. Bu yaralanmaların tedavisinde amaç, hastanın erken hareketini sağlayan kararlı tespiti elde etmektir (Şekil 3). ${ }^{[14]}$

İpsilateral kalça osteoartriti, femur başının ipsilateral avasküler nekrozu, enflamatuvar artrit, kötü kemik kalitesine sahip instabil kırık paterni, ihmal edilmiş kırıklar ve başarısız internal tespit yapılmış hasta grubunda ilk seçenek olarak hemiartroplasti önerilmektedir. ${ }^{[15]}$ Bunun dışındaki tüm olgularda osteosentez birinci tedavi yöntemi olarak tercih edilmelidir.

Trokanterik bölge kırıklarının tespitinde çeşitli medüller kanal içi ve dışı tespit materyalleri geliş̧irilmiş olup, ideal implantın ne olduğu hala tartışma konusudur. Kanal dışı tespitin bilinen implantı olan dinamik kalça vidası (DHS), intertrokanterik kırıkların tedavisi için altın standart olarak kabul edilmiştir. ${ }^{[15]}$ Bazı yazarlar, kanal içi kalça çivi tespitinin belirli hasta alt grupları için, özellikle de ters oblik paternli kırıklar, lateral duvar veya posteromedial parçalı kırıklar ve femur boynuna uzanan kırıklar veya subtrokanterik bölgeler gibi stabil olmayan kırıklar için üstün olduğunu öne sürmüşlerdir. ${ }^{16-18]}$

Aros ve ark., 65 yaş üstü trokanterik kırıkları inceledikleri çalışmalarında; kayan kalça vidasına kıyasla kanal içi çivilemenin daha yüksek bir revizyon cerrahisi oranıyla ilişkili olduğunu bildirmiştir. Daha yüksek revizyon cerrahisi oranı ve intramedüller çivilemenin maliyetleri dikkate alındığında intertrokanterik femur 
kırıklarının tedavisi için kanal içi çivilemeyi rutin kullanımda önermemektedir. [19] Parker ve ark., kanal içi çivi ve kayan kalça vidasını karşılaştıran çalışmalarında; femurun ameliyat sırasında ve sonrasında artan kırılma riski ve kanal içi çivi ile ilişkili revizyon cerrahisi oranının artması göz önüne alındığında, kayan kalça vidasının intertrokanterik kırıkların tedavisinde üstün olduğu sonucuna varmışlardır. ${ }^{[20]}$ Arirachakaran ve ark., yaşlı pertrokanterik kırıkların tedavisinde proksimal femoral çivi (PFN) ve DHS'nin her birisinin iyi birer seçim olabileceğini bildirmiştir. [16]

Kanal içi çivi tespiti ameliyat sonrası erken dönemde tam yük verme açısından kısa vadeli bir avantaja sahiptir. Uzun vadeli avantajları ise tartışmalıdır. ${ }^{[21,22]}$ Potansiyel olarak; daha düşük kan kaybı, daha az periosteal dolaşımda bozulma ve perkütan olarak yerleştirilebilme özellikleri kanal içi çivilemenin kayan kalça vidasına üstünlükleridir. ${ }^{[19]}$

\section{AMELIYAT ÖNCESI PLANLAMA}

Yaşlı kalça kırıklarında cerrahi planlama yapılırken konuyu çok boyutlu değerlendirmek yararlı olacaktır. Tedavide osteosentez birinci seçenek olsa da tatmin edici kırık redüksiyonunun sağlanamaması ya da osteoporozun neden olduğu düşük kemik kalitesinin stabil tespite izin vermemesi gibi hallerin de ortaya çıkabileceği unutulmamalıdır. Proksimal femoral bölge travmalarında cerrahi hazırlık ve malzeme seçiminde artroplasti materyallerini de tüm türevleriyle hazır bulundurulması medikolegal açıdan ve tedavinin tek seansta sonuçlandırılabilmesi için önemlidir. Zira yukarıda sayılan nedenlerden ötürü cerrahi uygulamada artroplastiye dönüş gerekebilir. Eğer artroplasti gerekliliği ortaya çıkarsa cerrahi yaklaşımda anterior, anterolateral, direkt lateral ya da posterior girişimlerden birisi tercih edilebilir. ${ }^{[22,23]}$

Öte yandan planlama yapılırken hasta pozisyonu supin ya da lateral dekubit tercih edilebilir. Her iki pozisyonda da ameliyathane şartlarının traksiyon kiti kullanmaya uygun olması önemlidir. Literatürde supin (sırtüstü) ya da lateral pozisyonda traksiyon masası kullanarak veya kullanmaksızın tespit yapıldığını bildiren yayınlar da bulunmaktadır. ${ }^{24,25]}$

Ameliyathane şartları, traksiyon masası mevcudiyeti, yeterli ve eğitimli personel varlı̆̆ı, mevcut implantlar ile uygulama setlerinin özellikleri ve cerrahın tecrübesi cerrahi planlamada temel öneme sahiptir.

\section{SONUÇ}

Yaşlı kalça kırıklarında uzayan yaşam süreleri ve artan konfor beklentileri göz önüne alındığında öncelikli tedavi tercihi osteosentez olarak ortaya çıkmaktadır.
İnstabil pertrokanterik kırıkların tedavisinde kanal içi çivileme tercih edilmelidir. Dengeli pertrokanterik kırıklarının cerrahi tespitinde implant seçimi ise cerrahın tecrübesi, ameliyathane şartları, sahip olunan ekipman ve/veya traksiyon masası varlığı gibi faktörlerle birlikte ele alınmalıdır.

\section{KAYNAKLAR}

1. Kastanis G, Topalidou A, Alpantaki K, Rosiadis M, Balalis K. Is the ASA score in geriatric hip fractures a predictive factor for complications and readmission? Scientifica (Cairo) 2016;2016:7096245. Crossref

2. Johnell O, Kanis JA. An estimate of the worldwide prevalence, mortality and disability associated with hip fracture. Osteoporos Int 2004;15(11):897-902. Crossref

3. Simunovic N, Devereaux PJ, Sprague $S$, Guyatt $\mathrm{GH}$, Schemitsch E, Debeer J, Bhandari M. Effect of early surgery after hip fracture on mortality and complications: systematic review and meta-analysis. CMAJ 2010;182(15):1609-16. Crossref

4. Butler M, Forte ML, Joglekar SB, Swiontkowski MF, Kane RL. Evidence summary: Systematic review of surgical treatments for geriatric hip fractures. Bone Joint Surg Am 2011;93(12):1104-15. Crossref

5. Bensafi H, Laffosse J-M, Giordano G, Dao C, Chiron P, Puget J. The percutaneous compression plate (PCCP) in the treatment of trochanteric hip fractures in elderly patients. Acta Orthop Belg 2006;72(3):314-9. https://www.researchgate.net/ publication/6897972_The_PerCutaneous_Compression_ Plate_PCCP_in_the_treatment_of_trochanteric_hip_ fractures_in_elderly_patients

6. Shetty $\mathrm{SH}$, Dhond $\mathrm{AB}$, Agarwal A, Kharat A, Singh A. Intertrochanteric fracture of femur in elderly - A comparative analysis between hemiarthroplasty and osteosynthesis. Int J Orthop Sci 2017;3(1):449-52. Crossref

7. Turesson E, Ivarsson K, Thorngren K-G, Hommel A. Hip fractures - treatment and functional outcome The development over 25 years. Injury 2018;49(12):2209-15. Crossref

8. Kim DC, Honeycutt MW, Riehl JT. Hip fractures: current review of treatment and management. Curr Orthop Prac 2019;30(4):385-94. https://sogacot.org/ hip-fractures-current-review-of-treatment-and-management/

9. Gjertsen J-E, Vinje T, Engesaeter LB, Lie SA, Havelin LI, Furnes $O$, Fevang JM. Internal screw fixation compared with bipolar hemiarthroplasty for treatment of displaced femoral neck fractures in elderly patients. J Bone Joint Surg Am 2010;92(3):619-28. Crossref

10. Chen W-C, Yu S-W, Tseng I-C, Su J-Y, Tu Y-K, Chen W-J. Treatment of undisplaced femoral neck fractures in the elderly. J Trauma 2005;58(5):1035-9. Crossref

11. Jansen $H$, Frey SP, Meffert RH. Subtrochanteric fracture: A rare but severe complication after screw fixation of femoral neck fractures in the elderly. Acta Orthop Belg 2010;76(6):77884. https://pubmed.ncbi.nlm.nih.gov/21302576/

12. Parker MJ, Khan RJK, Crawford J, Pryor GA. Hemiarthroplasty versus internal fixation for displaced intracapsular hip fractures in the elderly. J Bone Joint Surg Br 2002;84$\mathrm{B}(8): 1150-5$. Crossref

13. Dai Z, Li Y, Jiang D. Meta-analysis comparing arthroplasty with internal fixation for displaced femoral neck fracture in the elderly. J Surg Res 2011;165(1):68-74. Crossref 
14. Pajarinen J, Lindahl J, Michelsson O, Savolainen V, Hirvensalo E. Pertrochanteric femoral fractures treated with a dynamic hip screw or a proximal femoral nail. J Bone Joint Surg $\mathrm{Br}$ 2005;87-B(1):76-81. Crossref

15. Sambandam SN, Chandrasekharan J, Mounasamy V, Mauffrey C. Intertrochanteric fractures: a review of fixation methods. Eur J Orthop Surg Traumatol 2016;26(4):339-53. Crossref

16. Arirachakaran A, Amphansap $\mathrm{T}$, Thanindratarn $\mathrm{P}$, Piyapittayanun $P$, Srisawat $P$, Kongtharvonskul J. Comparative outcome of PFNA, Gamma nails, PCCP, Medoff plate, LISS and dynamic hip screws for fixation in elderly trochanteric fractures: a systematic review and network meta-analysis of randomized controlled trials. Eur J Orthop Surg Traumatol 2017;27(7):937-52. Crossref

17. Haidukewych GJ, israei TA, Berry DJ. Reverse obliquity fractures of the intertrochanteric region of the femur. J Bone Joint Surg Am 2001;83(5):643-50. Crossref

18. Kyie RF. Eliis TJ, Tempieman DC. Surgical treatment of intertrochanteric hip fractures with associated femoral neck fractures using a sliding hip screw. J Orthop Trauma 2005;19(1): I-4. Crossref

19. Aros B, Tosteson ANA, Gottlieb DJ, Koval KJ. Is a sliding hip screw or IM nail the preferred implant for intertrochanteric fracture fixation? Clin Orthop Relat Res 2008;466(11):282732. Crossref
20. Parker MJ, Handoll HH. Gamma and other cephalocondylic intramedullary nails versus extramedullary implants for extracapsular hip fractures in adults. Cochrane Database Syst Rev 2008;16(3):CD000093. Crossref

21. Chua ITH, Rajamoney GN, Kwek EBK. Cephalomedullary nail versus sliding hip screw for unstable intertrochanteric fractures in elderly patients. J Ortho Surg 2013;21(3):30812. Crossref

22. Kwon MS, Kuskowski M, Mulhall KJ, Macaulay W, Brown TE, Saleh KJ. Does surgical approach affect total hip arthroplasty dislocation rates? Clin Orthop Relat Res 2006;447:34-8. Crossref

23. Matta JM, Shahrdar C, Ferguson T. Single-incision anterior approach for total hip arthroplasty on an orthopaedic table. Clin Orthop Relat Res 2005;441:115-24. Crossref

24. Parker MJ, Bowers TR, Pryor GA. Sliding hip screw versus the Targon PF nail in the treatment of trochanteric fractures of the hip. J Bone Joint Surg Br 2012;94-B(3):391-7. Crossref

25. Turgut A, Kalenderer Ö, Günaydın B, Önvural B, Karapınar $\mathrm{L}$, Aguş $\mathrm{H}$. Fixation of intertrochanteric femur fractures using Proximal Femoral Nail Antirotation (PFNA) in the lateral decubitus position without a traction table. Acta Orthop Traumatol Turc 2014;48(5):513-20. Crossref 